\title{
Cognitive dysfunctions in recreational and dependent cocaine users: role of attention-deficit hyperactivity disorder, craving and early age at onset
}

Matthias Vonmoos, Lea M. Hulka, Katrin H. Preller, Daniela Jenni, Markus R. Baumgartner, Rudolf Stohler, Karen I. Bolla and Boris B. Quednow

\section{Background}

Dependent cocaine users consistently display cognitive deficits but cognitive performance of recreational cocaine users has rarely been investigated.

\section{Aims}

To examine whether cognitive performance is impaired in relatively pure recreational and dependent cocaine users.

\section{Method}

The cognitive performance of recreational $(n=68)$ and dependent cocaine users $(n=30)$ was compared with the performance of stimulant-naive controls $(n=68)$ employing an extensive neuropsychological test battery. Moreover, the impact of attention-deficit hyperactivity disorder (ADHD) symptoms, craving and early age at onset was analysed.

\section{Results}

Dependent cocaine users display broad cognitive impairments in the domains of attention, working memory, declarative memory and executive functions. The performance of recreational cocaine users in all four domains was intermediate between that of controls and dependent users and they displayed significant deficits foremost in the domains of attention and working memory. In addition, ADHD symptoms, craving and age at onset were important modulators of cognitive function in cocaine users.

\section{Conclusions}

Cognitive deficits occur at a recreational and non-dependent level of cocaine use. Cocaine use and ADHD seem to have mutually aggravating effects on cognitive impairment.

\section{Declaration of interest}

None.
With an annual number of around four million users, cocaine is currently the second most frequently used illicit drug in Europe. ${ }^{1}$ Given its addictive potential ${ }^{2,3}$ and negative health consequences, ${ }^{2,4}$ the use of cocaine is regarded as a major public health issue. ${ }^{2,4}$ For more than two decades, research has tried to examine the long-term impact of cocaine by focusing on dependent cocaine users. Evidence has accumulated that addictive cocaine use leads to neuroadaptive changes and dopaminergic alterations, mainly exerted in the frontostriatal network. ${ }^{5-9}$ Imaging studies in chronic cocaine users have repeatedly reported reductions in grey matter density in the dorsolateral prefrontal cortex, the anterior cingulate cortex and the orbitofrontal cortex,${ }^{10-14}$ areas critically involved in several cognitive functions. ${ }^{15}$ Accordingly, cognitive deficits in chronic cocaine users have been linked to structural and functional alterations primarily of the prefrontal cortex..$^{5,6,9,16}$ The recent literature is characterised by a consensus that cocaine dependence is associated with significant neuropsychological impairment, although the aetiology and the severity of these impairments are a matter of ongoing debate..$^{5,16-18}$ Existing studies with dependent users indicate persisting cognitive impairments including deficits predominantly in the domains of attention, working and declarative memory, and, less consistently, in the ill-defined concept of executive functions. ${ }^{5,10,16-21}$ However, given that these previous studies differed in their inclusion and exclusion criteria regarding comorbid psychiatric diseases, polytoxic drug-use history, abstinence time and verification of self-reported drug intake, the specific impact of chronic cocaine use on cognitive processes has been difficult to determine.

Whereas most of these studies focused on the chronic misuse of cocaine, relatively little is known about the substantial number of recreational but non-dependent cocaine users (recreational users). ${ }^{1}$ Moreover, in comparison with studies with dependent cocaine users, the investigation of recreational users has several advantages, as they (a) are not (or not yet) addicted, (b) are less burdened by psychiatric comorbidities, ${ }^{22}$ (c) usually unmedicated with psychotropic drugs, and (d) mostly display less polytoxic drug use. It is only recently that research has started to systematically investigate the possible cognitive effects of recreational cocaine use. ${ }^{23}$ Preliminary data from small samples of recreational users indicate that small and infrequent doses of cocaine affect different cognitive components such as attention, memory or components of executive functions. ${ }^{23-29}$ However, these studies lacked a unique definition of recreational cocaine use (recreational cocaine use was either defined by cocaine use below a certain level or by not matching dependency criteria according to DSM-IV ${ }^{30}$ ), mostly relied on simple self- reported drug use without objective verification, or tested only very small and predominantly male samples with mainly polytoxic drug use patterns. As a consequence, after more than two decades of research and despite concern about public health effects, there is still no clarification on the relationship between the extent of cocaine use and the characteristics of cognitive impairments.

To date, analyses of regular cocaine users categorised by groups of differing consumption patterns have been lacking. Our aim, therefore, was to investigate a large sample of recreational users, dependent users and matched stimulant-naive healthy controls with a comprehensive neuropsychological test battery to examine whether cognitive performance is impaired in relatively pure recreational and dependent cocaine users. Any differences in cognitive performance would have implications notably with regard to risk markers, prevention and treatment 
implications. ${ }^{5,12,20}$ We expect to find considerable cognitive deficits in dependent users and similar, but less pronounced, cognitive impairments in recreational users, as we recently reported deficits in early information processing and blue-yellow colour vision in recreational users suggesting alterations of catecholamine neurotransmission. ${ }^{31,32}$ Although psychiatric comorbidities such as attention-deficit hyperactivity disorder (ADHD) and depression are frequently found in dependent cocaine users, ${ }^{33,34}$ their impact has scarcely been investigated so far. Thus, we conducted a comprehensive psychiatric diagnostic interview and additionally assessed symptoms of ADHD and depression with self-report questionnaires. Finally, by performing urine and hair toxicology analyses, we were uniquely able to objectively characterise not only recent drug use but also drug use over the past 6 months.

\section{Method}

\section{Participants}

A total of 68 recreational cocaine users, 30 dependent users and 68 cocaine-naive controls were included in the study (recruitment and selection details in online data supplement Method DS1). The three groups did not differ significantly in age, gender, smoking habits and verbal IQ. Exclusion criteria for all participants were acute or previous neurological disorders or head injury, any clinically significant medical diseases and use of prescription drugs affecting the central nervous system. Additional exclusion criteria for the control group were all acute or previous Axis I DSM-IV psychiatric disorders $^{30}$ including ADHD and any form of addiction, except nicotine, or regular illegal drug use (lifetime use $>15$ occasions) with the exception of occasional cannabis use. Specific exclusion criteria for the cocaine user groups were use of opioids, a polytoxic drug use pattern according to DSM-IV and acute or previous Axis I DSM-IV adult psychiatric disorders with the exception of cocaine, cannabis and alcohol misuse, history of affective disorders (acute major depression was excluded) or ADHD. None of the cocaine users was helpseeking in our department. Inclusion criteria for the two user groups were cocaine as the primary drug, cocaine use of $>0.5 \mathrm{~g}$ per month, and an abstinence duration of $<6$ months. Cocaine dependence was diagnosed according to the DSM-IV criteria, ${ }^{30}$ with only dependent cocaine users fulfilling these criteria. Participants were asked to abstain from illegal substances for at least $72 \mathrm{~h}$ and not to consume alcohol for $24 \mathrm{~h}$ before the testing session. Adherence with these instructions was controlled by urine and 6-month hair toxicologies (online Method DS2). The study was approved by the Cantonal Ethics Committee of Zurich. All participants provided written informed consent and were compensated for their participation.

\section{Procedure}

The present data were collected as part of the longitudinal Zurich Cocaine Cognition Study $\left(\mathrm{ZuCo}^{2} \mathrm{St}\right){ }^{32}$ Trained psychologists conducted a Structured Clinical Interview (SCID-I) ${ }^{35}$ according to DSM-IV procedures. Drug use was assessed by means of a structured and standardised Interview for Psychotropic Drug Consumption. ${ }^{36}$ For the estimation of verbal intellectual performance, the Mehrfachwahl-Wortschatz-Intelligenztest (MWT-B) was applied. ${ }^{37}$ The brief version of the Cocaine Craving Questionnaire (CCQ) was used to capture current cocaine craving. ${ }^{38}$ Smoking habits were assessed by the Fagerström Test of Nicotine Dependence. $^{39}$ The Beck Depression Inventory $(\mathrm{BDI})^{40}$ measured the current severity of depression and the ADHD Self-Rating scale $(\mathrm{ADHD}-\mathrm{SR})^{41}$ focused on the diagnosis of ADHD in adulthood according to DSM-IV criteria. Subsequently, participants underwent a comprehensive neuropsychological test battery as described below. Participants were allowed to take a break at any time and smoking was permitted during the breaks.

\section{Neuropsychological assessment}

The test battery comprises four tests of the Cambridge Neuropsychological Test Automated Battery (CANTAB): ${ }^{42}$ rapid visual processing (RVP), spatial working memory (SWM), intra/extradimensional set shifting (IED), paired associates learning (PAL); a German version of the Rey Auditory Verbal Learning Test (RAVLT) ${ }^{43}$ and the Letter Number Sequencing Task (LNST). ${ }^{44}$ With regard to data reduction and specific analyses, 15 predefined main cognitive test parameters were $z$-transformed on the basis of means and standard deviations of the control group. These parameters were reduced to the four cognitive domains commonly used in cocaine research: ${ }^{16-18,21}$ attention, working memory, declarative memory and executive function according to theoretical a priori considerations (a detailed description can be found in online Method DS3). Furthermore, these four $z$-scored domains were equally integrated into a global cognitive index (GCI).

\section{Statistical analysis}

Statistical analyses were performed with IBM SPSS Statistics 19.0 for Windows. Frequency data were analysed by means of Pearson's chi-squared test and quantitative data by analyses of variance (ANOVA). Based on significant main effects, Sidak post hoc comparisons were performed. To control for demographic inequalities, the variables age and verbal IQ were introduced as covariates in analyses of covariance (ANCOVA) with linear group contrasts. Correlation analyses (Pearson's product-moment) to relate drug-use parameters to cognitive performance were conducted across a combined user group. Cumulated cocaine use and weekly use in grams were $1 n$-transformed for statistical analyses because of the highly skewed distribution and the resulting deviation from the normal distribution (Shapiro-Wilk $W<0.001$ ). The effect of depression, ADHD, cocaine craving, recent cocaine use (positive urine test) and age at onset on cognitive performance was examined by correlation analyses and ANCOVA subgroup comparisons additionally corrected for severity of cocaine use. The effect of craving status was investigated because previous studies reported that craving for food and nicotine has an impact on cognitive functioning. ${ }^{45,46}$ Multiple logistic regressions were used to estimate odds ratios associated with the use of cocaine and cognitive performance. The odds ratios were left unadjusted because the values decisive for the group assignment were already adjusted for age and verbal IQ.

\section{Results}

\section{Demographic characteristics and drug use}

The groups did not differ regarding age, gender distribution, smoking status and verbal IQ but dependent users had fewer years of education than the controls and recreational users (Table 1). As expected, dependent users displayed higher BDI and ADHD-SR sum scores than controls and recreational users, whereas recreational users showed higher scores than controls.

Dependent cocaine users had more than eightfold higher concentrations of cocaine and metabolites compared with recreational users in their hair samples (Table 2). Nonetheless, recreational users were regular users with a mean weekly consumption of about $1 \mathrm{~g}$ of cocaine but without fulfilling the 


\begin{tabular}{|c|c|c|c|c|c|c|c|c|}
\hline & $\begin{array}{c}\text { Stimulant-naive } \\
\text { controls }\end{array}$ & $\begin{array}{l}\text { Recreational } \\
\text { cocaine users }\end{array}$ & $\begin{array}{l}\text { Dependent } \\
\text { cocaine users }\end{array}$ & $F$ & $\chi^{2}$ & $t$-test & $\begin{array}{l}\text { d.f., } \\
\text { d.f.err }\end{array}$ & $P$ \\
\hline$n(\%)$ & $68(41)$ & $68(41)$ & $30(18)$ & & & & & \\
\hline Age, years: mean (s.d.) & $30.3(9.2)$ & $28.7(6.2)$ & $32.5(9.0)$ & 2.386 & & & 2,163 & 0.10 \\
\hline Gender (female/male), $n$ & $21 / 47$ & $18 / 50$ & $8 / 22$ & & 0.375 & & 2 & 0.83 \\
\hline Smoking $(y / n), n$ & $53 / 15$ & $53 / 15$ & $24 / 6$ & & 0.061 & & 2 & 0.97 \\
\hline Verbal IQ (MWT-B), mean (s.d.) & $104.4(9.7)$ & $103.2(9.6)$ & $99.7(9.1)$ & 2.457 & & & 2,163 & 0.09 \\
\hline School education, years: mean (s.d.) & $10.7(1.8)$ & $10.5(2.0)$ & $9.5(1.2)^{\star * \dagger}$ & 4.822 & & & 2,163 & 0.01 \\
\hline BDI sum score (0-63), mean (s.d.) & $4.6(4.4)$ & $7.4(6.1)^{*}$ & $11.8(8.6)^{* * * *}$ & 15.009 & & & 2,163 & $<0.001$ \\
\hline BDI depression status (yes/no), ${ }^{\mathrm{b}} n$ & $5 / 63$ & $17 / 51$ & $12 / 18$ & & 15.066 & & 2 & $<0.001$ \\
\hline ADHD-SR sum score (0-22), mean (s.d.) & $7.6(4.8)$ & $13.2(9.0)^{* * *}$ & $17.1(8.7)^{* * *^{\dagger}}$ & 19.517 & & & 2,163 & $<0.001$ \\
\hline ADHD DSM-IV (yes/no), ${ }^{\mathrm{C}} n$ & $0 / 68$ & $14 / 54$ & $8 / 22$ & & 18.266 & & 2 & $<0.001$ \\
\hline Craving for cocaine (0-70), mean (s.d.) & - & $19.0(9.1)$ & $20.3(11.4)$ & & & 0.598 & 1,96 & 0.55 \\
\hline \multicolumn{9}{|c|}{$\begin{array}{l}\text { MWT-B, Mehrfachwahl-Wortschatz-Intelligenztest; BDI, Beck Depression Inventory; ADHD, attention-deficit hyperactivity disorder; ADHD-SR, ADHD Self-Rating Scale. } \\
\text { a. Significant } P \text {-values are shown in bold. Statistical tests: ANOVA (all groups), } \chi^{2} \text { test (all groups) for frequency data or independent } t \text {-test (Cocaine users only). } \\
\text { b. Cut-off } \geqslant 11 \text {. } \\
\text { C. Cut-off DSM-IV criteria. } \\
\text { Significant Sidak post hoc test } v \text {. control group: }{ }^{\star} P<0.05 \text {; }{ }^{* \star} P<0.01 ;{ }^{* \star *} P<0.001 \text {. } \\
\text { Significant Sidak post hoc test } v \text {. recreational users group: }{ }^{\star} P<0.05 \text {; }{ }^{\star} P<0.01 \text {. }\end{array}$} \\
\hline
\end{tabular}

DSM-IV criteria for dependence (41 recreational users met the criteria for cocaine abuse). The main route of administration was intranasal; only three dependent users were primarily inhaling the drug ( 2 free-base, 1 coca paste). In the urine samples, 10 recreational users and 12 dependent users tested positive for cocaine. However, we decided not to exclude them but to investigate the acute and post-acute effects of the drug. Online Table DS1, a more detailed version of Table 2 that also includes details of the patterns and amount of other drug and alcohol use by the three groups, shows that the hair samples revealed a clear domination of cocaine compared with other illegal drug use.

\section{Neurocognitive measures}

The ANCOVA for the GCI showed a significant group effect including a clear linear trend $(P<0.001)$, and significant pair-wise comparisons between all three groups (Fig. 1, Table 3 and online Fig. DS1), indicating global cognitive impairment in both cocaine user groups. Likewise, all four domains $(P<0.001)$ and 12 of 15 test parameters $(P<0.05-0.00001$, except the two IED parameters and the SWM strategy score) displayed significant linear trends, suggesting robust dose-response relationships (Table 3 and online Table DS2 for a more detailed analysis including all parameters). In all domains, recreational and dependent users differed significantly from controls. Additionally, the domains working memory and executive functions showed significant group differences between recreational and dependent users. The single test parameters within the attention, working memory and declarative memory domains (detailed RAVLT analysis, online Fig. DS2) showed similar results. However, the effect in the executive function domain was mainly driven by a strong effect regarding RAVLT recall consistency and, to a lesser degree, by the SWM strategy score, whereas the two IED parameters did not show any substantial group differences (detailed IED analysis, online Fig. DS3).

Correlation analyses within the total group of cocaine users $(n=98)$ revealed that the GCI and the domains working memory, declarative memory and executive functions were all inversely

\begin{tabular}{|c|c|c|c|}
\hline Cocaine & $\begin{array}{l}\text { Stimulant-naive controls } \\
\qquad(n=68)\end{array}$ & $\begin{array}{l}\text { Recreational cocaine users } \\
\qquad(n=68)\end{array}$ & $\begin{array}{l}\text { Dependent cocaine users } \\
\qquad(n=30)\end{array}$ \\
\hline Times per week, ${ }^{\mathrm{b}}$ mean (s.d.) & - & $1.1(1.0)$ & $2.9(2.6)$ \\
\hline Grams per week, ${ }^{\mathrm{b}}$ mean (s.d.) & - & $1.1(1.4)$ & $7.9(15.8)$ \\
\hline Years of use, mean (s.d.) & - & $6.5(4.0)$ & $9.4(6.5)$ \\
\hline Maximum dose, g/day: mean (s.d.) & - & $3.5(2.5)$ & $9.4(8.4)$ \\
\hline Cumulative dose, g: mean (s.d.) & - & $519.7(751.2)$ & $5500.9(9635.2)$ \\
\hline Last consumption, days: mean (s.d.) & - & $27.5(37.6)$ & $21.0(33.6)$ \\
\hline \multicolumn{4}{|l|}{ Hair analysis, mean (s.d.) } \\
\hline Cocaine $\mathrm{pg} / \mathrm{mg}^{\mathrm{c}}$ & - & 2739 (4628) & 22164 (32 609) \\
\hline Benzoylecgonine pg/mg ${ }^{\mathrm{C}}$ & - & $546(919)$ & 5048 (7711) \\
\hline Cocaethylene $\mathrm{pg} / \mathrm{mg}^{\mathrm{c}}$ & - & $276(316)$ & $2006(3656)$ \\
\hline Norcocaine $\mathrm{pg} / \mathrm{mg}^{\mathrm{c}}$ & - & $62(101)$ & $586(758)$ \\
\hline Cocaine $_{\text {total }} \mathrm{pg} / \mathrm{mg}^{\mathrm{c}, \mathrm{d}}$ & - & $3347(5580)$ & $27798(40226)$ \\
\hline Urine toxicology (negative/positive), ${ }^{\mathrm{e}} n$ & $68 / 0$ & $57 / 10$ & $18 / 12$ \\
\hline \multicolumn{4}{|c|}{$\begin{array}{l}\text { a. See online Table DS1 for a more detailed version of this table that includes details for other drug and alcohol use. Use frequency, duration of use and cumulative doses are } \\
\text { averaged within the total group. } \\
\text { b. Average use during the past } 6 \text { months. } \\
\text { c. Cut-off value for cocaine: } 500 \mathrm{pg} / \mathrm{mg}^{47} \text { Hair samples were voluntary and data are missing for three controls and one recreational user. } \\
\text { d. Cocaine } \text { total ( }^{2} \text { cocaine }+ \text { benzoylecgonine + norcocaine) is a more robust procedure for discrimination between incorporation and contamination of hairs. }{ }^{48} \\
\text { e. Cut-off value for cocaine: } 150 \mathrm{ng} / \mathrm{ml}{ }^{49} \text { Urine toxicology test data are missing for one recreational user. }\end{array}$} \\
\hline
\end{tabular}


associated with cumulative cocaine dose, duration of cocaine use, cocaine metabolites benzoylecgonine and norcocaine in the hair, and a composite index reflecting the severity of cocaine use (Table 4; intercorrelation of cocaine use parameters, online Table DS3). Interestingly, the domain attention was only strongly correlated with the cumulative cocaine dose. The relatively high correlations in the domain executive functions were again driven by both the RAVLT and SWM parameter, whereas no associations were found for the two IED measures (single test correlation analysis, online Table DS4).

\section{ADHD, age at onset, craving, depression and acute drug effects}

Our analysis of ADHD and craving subgroups, by further splitting user groups according to predefined criteria ${ }^{41}$ (yes/no fulfilling DSM-IV criteria on ADHD-SR) or median split (low/high, CCQ $\leqslant 16$ ) suggested an impact of these variables on cognitive performance (Fig. 2). The ANCOVAs showed significant group effects for $\operatorname{ADHD}(F(4,158)=9.56, P<0.001)$ and craving subgroups $(F(4,158)=9.35, \quad P<0.001)$. The presence of craving additionally decreased cognitive performance only in recreational users $(d=0.26)$ (Fig. 2b), an ADHD diagnosis had a detrimental effect on cognitive functioning in both recreational $(d=0.30)$ and dependent users $(d=0.33)$ (Fig. 2a). Notably, recreational and dependent users without ADHD still significantly differed from controls. A combined analysis of ADHD and craving status in an integrated group of cocaine users confirmed this assumption by revealing a significant main effect for group $(F(4,158)=7.66$, $P<0.001$ ), whereby the controls differed significantly from all the cocaine user groups (Fig. 2c).

Age at onset of cocaine use played a crucial role $(F(2,160)=10.92, P<0.001)$, as users starting cocaine use before the age 19 years performed significantly worse than users with a later age at onset $(d=0.66)$. Both users groups differed substantially from the control group $\left(d_{\leqslant 18}=1.10, d_{>18}=0.43\right)$ (Fig. 3).

Splitting the user groups and controls according to a predefined depression criterion $^{50}$ (low/mild-strong, BDI $\geqslant 11$ ) showed a significant group effect $(F(5,157)=7.41, P<0.001)$ reflecting a weak additive impact of depressive symptoms on cognitive performance only in recreational users $(d=0.28)$. Also, cocaine users without depression differed significantly from controls without depression (online Fig. DS4).

To test the influence of recent cocaine use, cocaine users were divided into users with positive $(n=22$, range $217-24888 \mathrm{ng} / \mathrm{ml}$, mean $3873 \mathrm{ng} / \mathrm{ml}$, s.d. $=6461 \mathrm{ng} / \mathrm{ml}$ ) and users with negative urine samples $(n=75)$ and compared with controls $(n=68)$. Results revealed significant group effects for the GCI $(F(2,160)=14.76, P<0.001)$. Pair-wise Sidak comparisons yielded still significant and relatively strong differences between controls and both user groups $\left(d_{n e g}=0.63, d_{p o s}=0.84\right)$, and users with positive urine samples showed slightly but non-significantly lower GCI scores than users with negative urine samples $(d=0.22)$. Similar patterns were found for all four domains (online Fig. DS5).

Multiple regression analyses conducted only in cocaine users confirmed that cumulative dose and duration of cocaine use were the best predictors of cognitive performance in contrast to psychopathological symptoms (online Table DS5).

\section{Risk threshold for cognitive impairments}

As the use of cocaine proved to be an important determinant for cognitive performance, odds ratios (ORs) were calculated to assess the risk of impairment when using cocaine. If a progressive clinical criterion of -1 standard deviation was applied to define a cognitive decline, the use of cocaine indicated significant relative risks for deficits in attention $(\mathrm{OR}=3.52,95 \%$ CI 1.60-7.72, $P<0.01)$, working memory $(\mathrm{OR}=3.08,95 \%$ CI $1.47-6.49, \quad P<0.01)$, declarative memory $(\mathrm{OR}=2.40,95 \% \mathrm{CI} 1.11-5.19, P<0.05)$ and

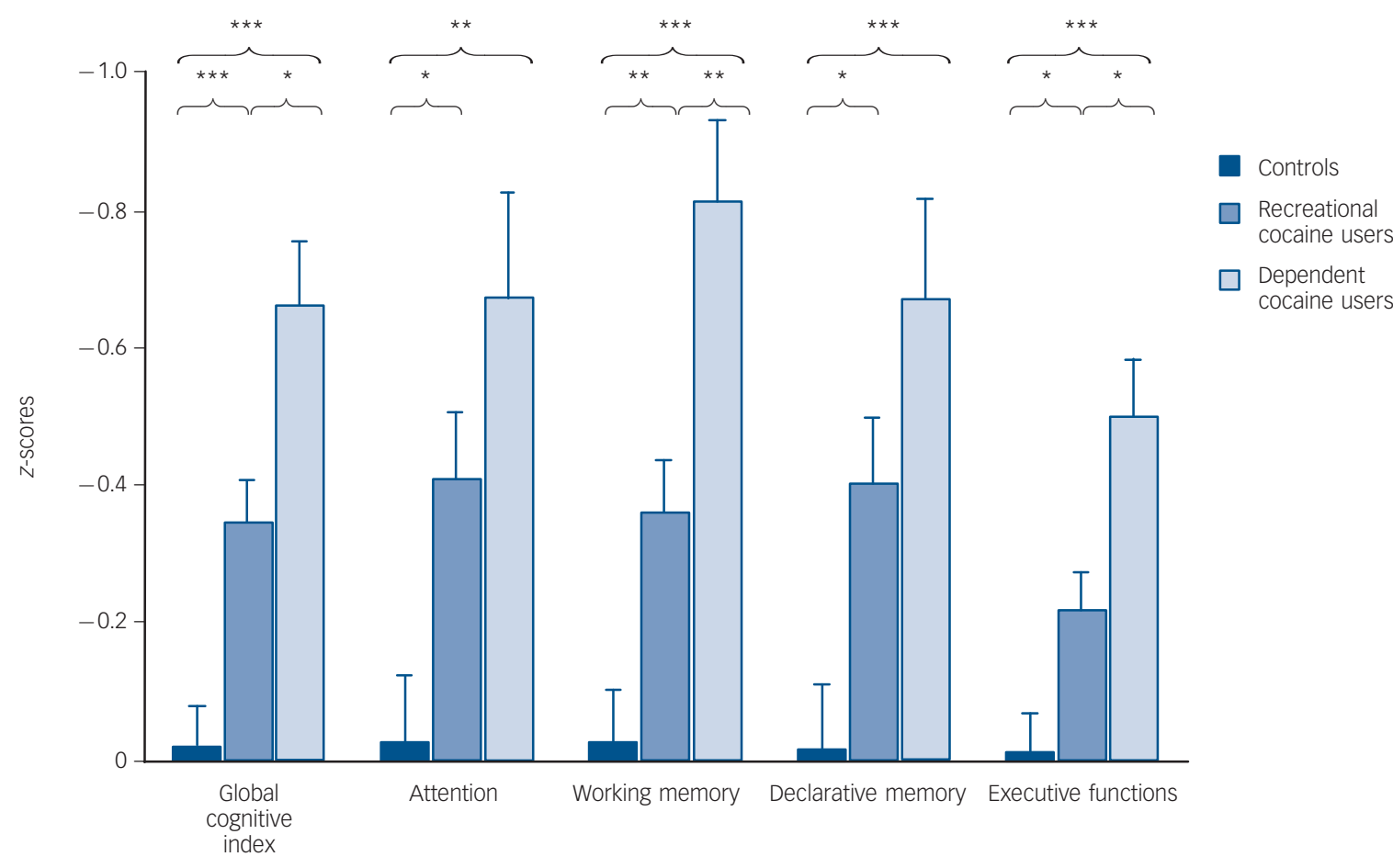

Fig. 1 Mean Z-scores and standard errors for the global cognitive index (GCl) and the four cognitive domains (values corrected for age and verbal IQ).

Sidak post hoc tests: ${ }^{*} P<0.05,{ }^{*} P<<0.01,{ }^{* * * P}<0.001$ 

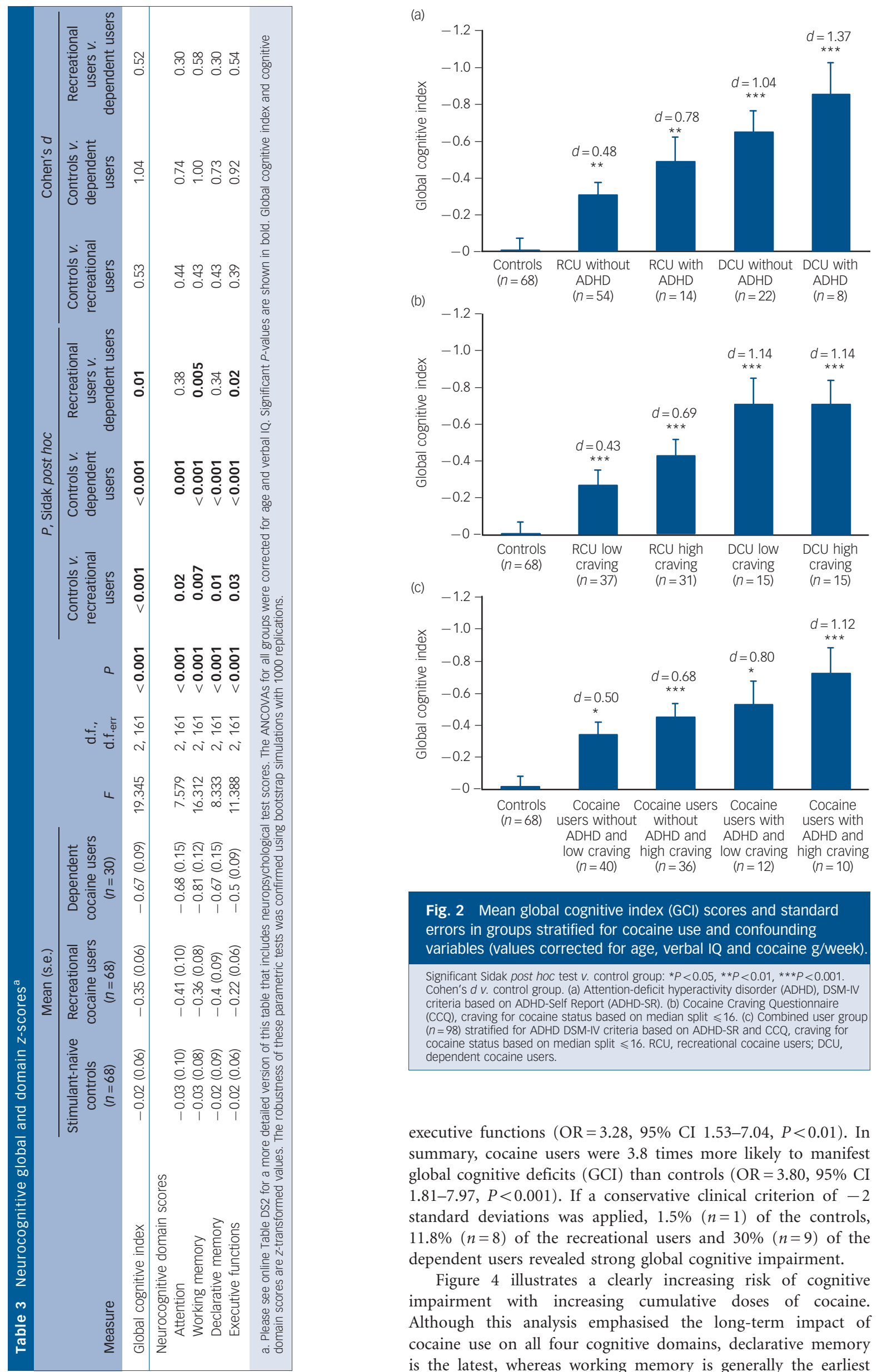

Fig. 2 Mean global cognitive index (GCI) scores and standard errors in groups stratified for cocaine use and confounding variables (values corrected for age, verbal IQ and cocaine g/week).

Significant Sidak post hoc test $v$. control group: ${ }^{*} P<0.05$, $* * P<0.01$, $* \star * P<0.001$. Cohen's $d v$. control group. (a) Attention-deficit hyperactivity disorder (ADHD), DSM-IV criteria based on ADHD-Self Report (ADHD-SR). (b) Cocaine Craving Questionnaire (CCQ), craving for cocaine status based on median split $\leqslant 16$. (C) Combined user group $(n=98)$ stratified for ADHD DSM-IV criteria based on ADHD-SR and CCQ, craving for cocaine status based on median split $\leqslant 16$. RCU, recreational cocaine users; DCU, dependent cocaine users.

executive functions $(\mathrm{OR}=3.28,95 \% \mathrm{CI} 1.53-7.04, P<0.01)$. In summary, cocaine users were 3.8 times more likely to manifest global cognitive deficits (GCI) than controls ( $\mathrm{OR}=3.80,95 \% \mathrm{CI}$ 1.81-7.97, $P<0.001$ ). If a conservative clinical criterion of -2 standard deviations was applied, $1.5 \%(n=1)$ of the controls, $11.8 \%(n=8)$ of the recreational users and $30 \%(n=9)$ of the dependent users revealed strong global cognitive impairment.

Figure 4 illustrates a clearly increasing risk of cognitive impairment with increasing cumulative doses of cocaine. Although this analysis emphasised the long-term impact of cocaine use on all four cognitive domains, declarative memory is the latest, whereas working memory is generally the earliest 
Table 4 Correlations between neurocognitive global and domain z-scores and cocaine use parameters in cocaine users

\begin{tabular}{|c|c|c|c|c|c|c|}
\hline & $n$ & $\begin{array}{l}\text { Global cognitive } \\
\text { index }\end{array}$ & Attention & Working memory & $\begin{array}{c}\text { Declarative } \\
\text { memory }\end{array}$ & $\begin{array}{l}\text { Executive } \\
\text { functions }\end{array}$ \\
\hline Cumulative dose, g: $\log ^{a}$ & 98 & $-0.50 * * *$ & $-0.31^{* *}$ & $-0.39 * * *$ & $-0.43^{\star * *}$ & $-0.42^{* * *}$ \\
\hline Cumulative dose, g: log, adjusted for age ${ }^{b}$ & 98 & $-0.47^{* * *}$ & $-0.34^{* * *}$ & $-0.34^{* * *}$ & $-0.39 * * *$ & $-0.37^{* * *}$ \\
\hline Times per week ${ }^{a}$ & 98 & -0.17 & & & & $-0.25^{\star}$ \\
\hline Grams per week log ${ }^{a}$ & 98 & & & & & \\
\hline Years of use $\mathrm{e}^{\mathrm{a}}$ & 98 & $-0.33^{* * *}$ & & $-0.33^{* * *}$ & $-0.29 * *$ & $-0.40^{* * *}$ \\
\hline Years of use, adjusted for age ${ }^{b}$ & 98 & $-0.28^{* *}$ & & $-0.25^{\star}$ & $-0.22^{\star}$ & $-0.35^{* * *}$ \\
\hline Maximum dose, g/day ${ }^{a}$ & 98 & $-0.26^{* *}$ & $-0.23^{*}$ & & $-0.27^{* *}$ & \\
\hline Cocaine Craving Questionnaire sum score $(0-70)^{a}$ & 98 & & & -0.18 & & \\
\hline \multicolumn{7}{|l|}{ Hair analysis $^{a}$} \\
\hline Cocaine $\mathrm{pg} / \mathrm{mg}$ & $97^{c}$ & $-0.22^{\star}$ & & & -0.20 & -0.18 \\
\hline Benzoylecgonine $\mathrm{pg} / \mathrm{mg}$ & $97^{c}$ & $-0.29 * *$ & -0.17 & $-0.24^{*}$ & $-0.28^{* *}$ & $-0.20^{*}$ \\
\hline Cocaethylene pg/mg & $97^{c}$ & & & & & \\
\hline Norcocaine pg/mg & $97^{\mathrm{C}}$ & $-0.28^{* *}$ & & $-0.26^{* *}$ & $-0.27^{* *}$ & $-0.21^{*}$ \\
\hline cocaine $_{\text {total }} \mathrm{pg} / \mathrm{mg}$ & $97^{\mathrm{C}}$ & $-0.24^{*}$ & & -0.17 & $-0.22^{*}$ & -0.19 \\
\hline Severity of Cocaine Use Index ${ }^{a, d}$ & 98 & $-0.40^{* \star *}$ & $-0.21^{*}$ & $-0.28^{* *}$ & $-0.37^{* * *}$ & $-0.42^{* * *}$ \\
\hline \multicolumn{7}{|c|}{$\begin{array}{l}\text { a. Pearson's product-moment correlation. } \\
\text { b. Partial correlation corrected for age. } \\
\text { C. Hair samples were voluntary and data are missing for one recreational user. } \\
\text { d. Severity of Cocaine Index use corresponds to the mean of the } z \text {-transformed parameters: cumulative dose, grams per week, years of use, maximum dose and hair analysis } \\
\text { Cocaine total. } \\
\text { Correlations with a } P \text {-level below } 10 \% \text { are shown, and significant correlations are marked: }{ }^{*} P<0.05 ;{ }^{* *} P<0.01 \text {; }{ }^{* * * P<0.001} \text {. }\end{array}$} \\
\hline
\end{tabular}

and most affected domain. Interestingly, a lifetime consumption of more than $1 \mathrm{~kg}$ cocaine seemed to strongly enhance the risk for cognitive impairment (Fig. 4a), whereas a lifetime consumption of more than $100 \mathrm{~g}$ was associated with an approximately $50 \%$ risk for mild cognitive impairment (Fig. $4 \mathrm{~b}$ ).

\section{Discussion}

\section{Main findings}

The aim of the present study was to examine whether cognitive performance is impaired in non-dependent recreational cocaine users and dependent cocaine users. In contrast to previous studies, hair toxicologies and comprehensive psychiatric diagnostics

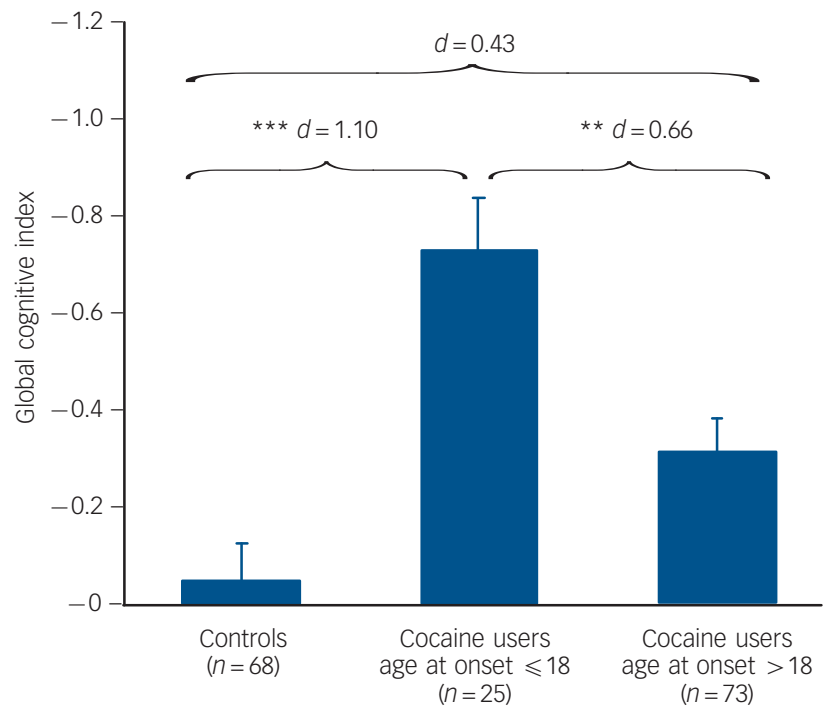

Fig. 3 Mean global cognitive index (GCl) scores and standard errors in groups stratified for age at onset for cocaine use (values are corrected for age, verbal IQ and cocaine use in years).

Group sizes $(n)$ are shown. Significant Sidak post hoc tests are marked: ${ }_{* *} P<0.01,{ }^{* * *} P<0.001$ allowed the investigation of relatively pure cocaine users with little psychiatric comorbidity. Moreover, this is the largest published sample of neuropsychologically examined cocaine users to date $(n=98)$ and the first study directly comparing the cognitive performance of stimulant-naive controls with both recreational and dependent users. The major finding of the present study is that intensive recreational users showed small but significant cognitive dysfunction, with dysfunction deteriorating further in dependent users. Recreational users displayed the strongest effects in the attention domain, whereas in dependent users working memory was most affected. Correlation and regression analyses revealed negative associations between cognitive performance and cocaine metabolites in the hair, cumulative cocaine dose and duration of cocaine use, suggesting that cognitive impairments might be partially cocaine-induced.

The influence of ADHD and cocaine craving on the cognitive functioning of cocaine users had not systematically been investigated before. We found that symptoms of ADHD and depression as well as craving for cocaine are important modulators of cognitive function in cocaine users, whereas recent cocaine use seemed to be less important. However, cognitive dysfunction is still present in cocaine users without the presence of craving, depression or ADHD symptoms. Finally, we demonstrated that the risk for cognitive impairment increases with early age at onset and ascending cumulative cocaine doses, in particular if estimated lifetime doses of $500 \mathrm{~g}$ to $1 \mathrm{~kg}$ cocaine are exceeded (Fig. 4).

\section{Comparison with findings from other studies}

The present results indicate impaired attention in both recreational and dependent users, with moderate to strong effect sizes respectively. As attention involves several subprocesses, it should be emphasised that our domain is primarily based on two RVP parameters measuring sustained attention. Our findings replicated previous reports on sustained attention deficits in dependent cocaine users ${ }^{17,21}$ but extended the current knowledge regarding relatively pure recreational users, as 


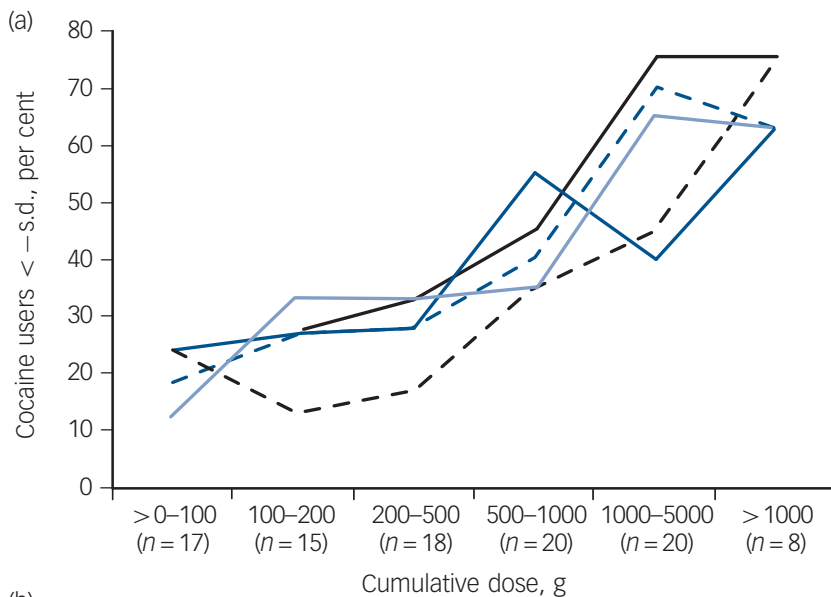

(b)

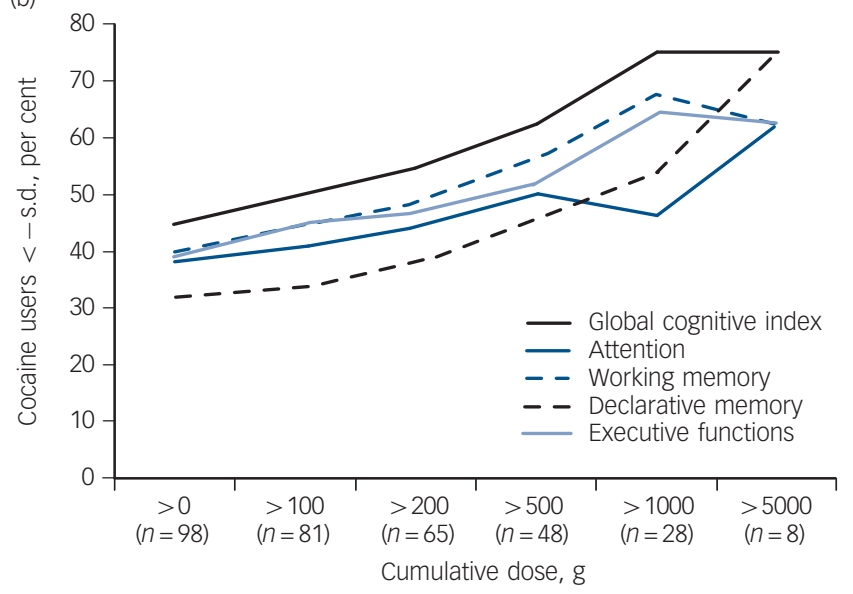

Fig. 4 (a) Percentage of cocaine users fulfilling the clinical cognitive criterion of below -1 standard deviation in the specific cumulative dose group. (b) Percentage of cocaine users fulfilling the clinical cognitive criterion of below -1 standard deviation in groups with (from left to right) ascending cumulative doses.

Domain cut-offs: global cognitive index s.d. $=-0.54$, attention s.d. $=-0.81$, working memory s.d. $=-0.70$, declarative memory s.d. $=-0.82$, executive functions s.d. $=-0.38$. Values are corrected for age and verbal IQ

attentional deficits have previously been indicated only in small samples $(n=13-18)$ of polytoxic recreational users. ${ }^{23,24,29}$

Regarding working memory, the strong effect sizes found for dependent users confirm previous findings, also mostly drawn from much smaller samples. ${ }^{17,18}$ In addition, in accordance with a recent study investigating a small sample of polydrug recreational users $(n=17)$, we found that recreational cocaine use is associated with subtle visuospatial working memory impairment. $^{29}$ Our results are the first to indicate small to moderate verbal working memory deficits in recreational users.

Furthermore, our study confirmed previous findings of broad deficits in verbal ${ }^{16,20,21}$ and visual learning and memory ${ }^{16,17,20}$ in dependent users. The only other report that studied recreational users described similar verbal memory deficits for recreational prescription stimulant users with $>80 \%$ cocaine co-use, but found no significant effects in a small group $(n=13)$ of recreational users with a low minimal inclusion threshold (use three times in the past 6 months). ${ }^{28}$ Thus, declarative memory dysfunction is associated not only with chronic but also with recreational cocaine use. However, compared with other domains declarative memory seemed to be least affected at cumulative cocaine doses $<500 \mathrm{~g}$.
Unlike in the other domains, the single executive function parameters displayed inconsistent results. Both IED parameters indicated no performance deficits in either user groups. On the contrary, the SWM strategy score demonstrated small to moderate, and the RAVLT recall consistency moderate to strong effects in recreational and dependent users. These inconsistencies are typical for the heterogeneous concept of executive functions reflecting varying task requirements and difficulty levels between studies. ${ }^{17}$ Nevertheless, the existing literature reported executive deficits in dependent users on complex but only scarcely on simple tasks. ${ }^{17}$ As $71 \%$ of the participants in the user groups achieved the highest IED stage, a ceiling effect can be assumed. Furthermore, we found strong correlations between the executive domain and several cocaine-use parameters confirming similar relationships that were found in earlier studies on dependent ${ }^{19}$ and recreational users. ${ }^{26}$

Sustained attention and working memory processes are both associated with increased activity in prefrontal, parietal and cingulate brain regions. ${ }^{15}$ Accordingly, the LNST involves the lateral prefrontal cortex, ${ }^{51}$ SWM performance is associated with the dorsolateral prefrontal cortex and ventrolateral prefrontal cortex, ${ }^{52,53}$ and the PAL depends on frontal and medial temporal lobe function. ${ }^{54}$ In-depth analysis of the RAVLT revealed that cocaine users primarily display learning and retrieval deficits, whereas recognition was less affected - a pattern specifically reported for prefrontal cortex lesions. ${ }^{55}$ Likewise, prefrontal cortex lesions have been related to impairments in recall consistency. ${ }^{56,57}$ Finally, glucose metabolism in the dorsolateral prefrontal cortex significantly predicted visual and verbal memory performance in participants who were cocaine addicted and in controls. ${ }^{16}$ Together with previous findings that dependent cocaine users display decreased grey matter volume and glucose metabolism in the orbitofrontal cortex and dorsolateral prefrontal cortex ${ }^{10-14,58-61}$ the neuropsychological profile therefore suggests that similar but less pronounced alterations in the prefrontal cortex might be present in recreational users.

We investigated potential cofactors frequently associated with cocaine use or commonly addressed as confounding factors for cognition such as ADHD and depressive symptoms. ${ }^{33,62}$ Moreover, craving for food ${ }^{45}$ and nicotine ${ }^{46}$ has been shown to have an impact on cognitive functioning but the specific impact of cocaine craving has not been investigated to date. Here, high craving and depression scores or an ADHD diagnosis further decreased the cognitive performance within the group of recreational users. Additionally, dependent users with clinically relevant ADHD symptoms displayed stronger cognitive deficits $(d=1.37)$ than dependent users without ADHD $(d=1.04)$, whereas neither craving nor depression symptoms had an additional effect in this group. Importantly, cocaine users without clinically relevant ADHD or depression scores and also with low craving scores still displayed significant cognitive deficits, whereas a combination of an ADHD diagnosis and high craving lead to the strongest impairments, similar to our results on early information processing. ${ }^{32}$ Regarding the impact of depression, our findings confirm a previous result reporting no additional effect of dysphoria on cognitive performance in a sample of predominantly dependent cocaine users ${ }^{18}$ but our data additionally indicate a small impact of depression at a recreational level of use.

Attention-deficit hyperactivity disorder is characterised by problems in attentional performance and inhibitory control and patients with ADHD on average perform worse than healthy controls on tests of attention and executive function. ${ }^{63}$ Nevertheless, the influence of ADHD symptoms on the cognition of cocaine users, in which ADHD is highly prevalent, had not been investigated previously. The exact pathogenesis underlying ADHD 
is still unknown, ${ }^{64}$ but as abnormalities within catecholamine systems and the prefrontal cortex seem to play a major role in $\mathrm{ADHD}^{64,65}$ and cocaine use, ${ }^{7,8}$ it can be assumed that similar pathologies might lead to a mutual aggravation of detrimental effects on cognitive performance.

In contrast to a previous finding, showing that cocaine users with a positive urine toxicology have slightly improved cognitive performances, ${ }^{18}$ users with positive cocaine urine tests displayed slightly worse cognitive scores in the present study. As urine toxicologies were performed by immunoassays, which are only presumptive and potentially biased by external factors, ${ }^{66}$ positive urine tests do not necessarily prove a violation of the requested 3-day cocaine retention period.

\section{Study limitations and future research}

The study has some limitations. First, cocaine dependency was diagnosed according to DSM-IV criteria. ${ }^{30}$ These criteria depend on introspection and self-report but do not consider features such as duration and amount of cumulative doses. Thus, some participants in the recreational users group might be misclassified as non-dependent. Second, although this is one of the first investigations employing hair analysis in a neurocognitive study with cocaine users, we can only rely on self-reports for all illegal drug use prior to 3-6 months (depending on hair length). This is, however, an inevitable constraint of all studies with illegal drug users. ${ }^{67}$ Third, a cross-sectional design cannot determine whether the cognitive deficits found in the cocaine users were pre-existent traits (vulnerability or resilience), drug-induced consequences or both. Hence, to answer this question we need to await the findings of the second part of the $\mathrm{ZuCo}^{2} \mathrm{St}$ longitudinal study in 2013. Finally, cocaine users participating voluntary in a study session lasting several hours require a certain level of motivation and cognitive functionality; we assume that the cocaine users in our sample are therefore not the most impaired individuals, and probably even perform relatively well. Thus, the cognitive impairments shown here might partially be underestimates for both recreational and dependent users.

In conclusion, our results confirmed that dependent cocaine use is associated with broad cognitive impairments in the domains attention, working memory, declarative memory and parts of executive functions. In all four domains, recreational users' performance was intermediate between that of controls and dependent users, and they displayed significant deficits, predominantly in the domains attention and working memory. This is in line with our previous work indicating catecholamine dysfunction at a recreational level of use. ${ }^{31,32}$ Furthermore, all cognitive domains displayed correlations with the long-term intake parameters duration and amount of cocaine use and specifically early age at onset was linked to considerable cognitive dysfunction. The neuropsychological profile suggests prefrontal cortex dysfunction as the common denominator of these cognitive impairments, which is in line with previous findings showing alterations to the frontostriatal dopamine system in addicted cocaine users. ${ }^{9,58,59}$ Additionally, cocaine use and ADHD seem to have mutually aggravating effects on cognitive impairments. Altogether these results indicate gradual impairments in both recreational and dependent cocaine users, and clinically relevant cognitive deficits seem to arise with long-term cocaine use, as best reflected by cumulative cocaine dose.

\section{Funding}

The study was supported by grants from the Swiss National Science Foundation (SNSF grant No. PP00P1-123516/1) and the Olga Mayenfisch Foundation.

\section{Acknowledgements}

We are grateful to the following for support with recruitment: Alex Bücheli (Streetwork Zürich), Roland Kowalewski (Research Group Substance Use Disorders, Clinic for General an Social Psychiatry, University Hospital of Psychiatry), Lars Stark and Thilo Beck (ARUD, Zurich), Eric La Serra (Klinik St. Pirminsberg. Psychiatrie-Dienste Süd, Kanton St. Gallen), we thank Joëlle Barthassat, Christina Gruber, Kathrin Küpeli, Franziska Minder and Claudia Schulz for excellent support and Dominique Eich-Höchli for critical comments on the manuscript.

Matthias Vonmoos, MSC, Lea M. Hulka, MSC, Katrin H. Preller, MSC, Daniela Jenni, MSc, Experimental and Clinical Pharmacopsychology, Department of Psychiatry, Psychotherapy and Psychosomatics, University Hospital of Psychiatry, University of Zurich, Switzerland; Markus R. Baumgartner, PhD, Center of Forensic Hairanalytics, Institute of Forensic Medicine, University of Zurich, Switzerland; Rudolf Psychotherapy and Psychosomatics, University Hospital of Psychiatry, University of Zurich, Switzerland; Karen I. Bolla, PhD, Department of Neurology, Johns Hopkins University School of Medicine, Baltimore, Maryland, USA; Boris B. Quednow, PhD Experimental and Clinical Pharmacopsychology, Department of Psychiatry, Psychotherapy and Psychosomatics, University Hospital of Psychiatry, University of Zurich, Switzerland

Correspondence: Boris B. Quednow, PhD, University Hospital of Psychiatry, Clinical and Experimental Pharmacopsychology, Lenggstrasse 31, $\mathrm{CH}-8032$ Clinical and Experimental Pharmacopsychology,

First received 7 Sept 2012, final revision 5 Dec 2012, accepted 18 Feb 2013

\section{References}

1 European Monitoring Centre for Drugs and Drug Addiction. Annual Report 2012: The State of the Drugs Problem in Europe. Publications Office of the European Union, 2012.

2 Nutt D, King LA, Saulsbury W, Blakemore C. Development of a rational scale to assess the harm of drugs of potential misuse. Lancet 2007; 369: 1047-53.

3 Wagner FA, Anthony JC. From first drug use to drug dependence; developmental periods of risk for dependence upon marijuana, cocaine, and alcohol. Neuropsychopharmacology 2002; 26: 479-88.

4 Degenhardt L, Hall, W. Extent of illicit drug use and dependence, and their contribution to the global burden of disease. Lancet 2012; 379: 55-70.

5 Beveridge TJ, Gill KE, Hanlon CA, Porrino LJ. Review. Parallel studies of cocaine-related neural and cognitive impairment in humans and monkeys. Philos Trans R Soc Lond B Biol Sci 2008; 363: 3257-66.

6 Garavan $H$, Hester R. The role of cognitive control in cocaine dependence. Neuropsychol Rev 2007; 17: 337-45.

7 Volkow ND, Fowler JS, Wang GJ, Baler R, Telang F. Imaging dopamine's role in drug abuse and addiction. Neuropharmacology 2009; 56: 3-8.

8 Volkow ND, Fowler JS, Wang GJ, Swanson JM. Dopamine in drug abuse and addiction: results from imaging studies and treatment implications. $\mathrm{Mol}$ Psychiatry 2004; 9: 557-69

9 Bolla K, Ernst M, Kiehl K, Mouratidis M, Eldreth D, Contoreggi $\mathrm{C}$ et al. Prefrontal cortical dysfunction in abstinent cocaine abusers. J Neuropsychiatry Clin Neurosci 2004; 16: 456-64.

10 Ersche KD, Barnes A, Jones PS, Morein-Zamir S, Robbins TW, Bullmore ET. Abnormal structure of frontostriatal brain systems is associated with aspects of impulsivity and compulsivity in cocaine dependence. Brain 2011; 134: 2013-24.

11 Franklin TR, Acton PD, Maldjian JA, Gray JD, Croft JR, Dackis CA, et al. Decreased gray matter concentration in the insular, orbitofrontal, cingulate, and temporal cortices of cocaine patients. Biol Psychiatry 2002; 51: 134-42.

12 Lucantonio F, Stalnaker TA, Shaham Y, Niv Y, Schoenbaum G. The impact of orbitofrontal dysfunction on cocaine addiction. Nat Neurosci 2012; 15 : $358-66$

13 Matochik JA, London ED, Eldreth DA, Cadet JL, Bolla KI. Frontal cortical tissue composition in abstinent cocaine abusers: a magnetic resonance imaging study. Neuroimage 2003; 19: 1095-102.

14 Sim ME, Lyoo IK, Streeter CC, Covell J, Sarid-Segal O, Ciraulo DA, et al. Cerebellar gray matter volume correlates with duration of cocaine use in cocaine-dependent subjects. Neuropsychopharmacology 2007; 32: 2229-37.

15 Cabeza R, Nyberg L. Imaging cognition II: An empirical review of 275 PET and fMRI studies. J Cogn Neurosci 2000; 12: 1-47.

16 Goldstein RZ, Leskovjan AC, Hoff AL, Hitzemann R, Bashan F, Khalsa SS, et al. Severity of neuropsychological impairment in cocaine and alcohol addiction: association with metabolism in the prefrontal cortex. Neuropsychologia 2004; 42: 1447-58. 
17 Jovanovski D, Erb S, Zakzanis KK. Neurocognitive deficits in cocaine users: a quantitative review of the evidence. J Clin Exp Neuropsychol 2005; 27 : 189-204.

18 Woicik PA, Moeller SJ, Alia-Klein N, Maloney T, Lukasik TM, Yeliosof O, et al. The neuropsychology of cocaine addiction: recent cocaine use masks impairment. Neuropsychopharmacology 2009; 34: 1112-22.

19 Bolla KI, Rothman R, Cadet JL. Dose-related neurobehavioral effects of chronic cocaine use. J Neuropsychiatry Clin Neurosci 1999; 11: 361-9.

20 Cunha PJ, Nicastri S, Gomes LP, Moino RM, Peluso MA. Neuropsychological impairments in crack cocaine-dependent inpatients: preliminary findings. Rev Bras Psiquiatr 2004; 26: 103-6.

21 Pace-Schott EF, Morgan PT, Malison RT, Hart CL, Edgar C, Walker M, et al. Cocaine users differ from normals on cognitive tasks which show poorer performance during drug abstinence. Am J Drug Alcohol Abuse 2008; 34 109-21.

22 Smith MJ, Thirthalli J, Abdallah AB, Murray RM, Cottler LB. Prevalence of psychotic symptoms in substance users: a comparison across substances. Compr Psychiatry 2009; 50: 245-50.

23 Colzato LS, van den Wildenberg WP, Hommel B. Reduced attentional scope in cocaine polydrug users. PLoS One 2009; 4: e6043.

24 Colzato LS, Hommel B. Recreational use of cocaine eliminates inhibition of return. Neuropsychology 2009; 23: 125-9.

25 Colzato LS, Huizinga M, Hommel B. Recreational cocaine polydrug use impairs cognitive flexibility but not working memory. Psychopharmacology (Berl) 2009; 207: 225-34.

26 Colzato LS, van den Wildenberg WP, Hommel B. Impaired inhibitory control in recreational cocaine users. PLOS One 2007; 2: e1143.

27 Rahman Q, Clarke CD. Sex differences in neurocognitive functioning among abstinent recreational cocaine users. Psychopharmacology (Berl) 2005; 181 374-80.

28 Reske M, Eidt CA, Delis DC, Paulus MP. Nondependent stimulant users of cocaine and prescription amphetamines show verbal learning and memory deficits. Biol Psychiatry 2010; 68: 762-9.

29 Soar K, Mason C, Potton A, Dawkins L. Neuropsychological effects associated with recreational cocaine use. Psychopharmacology (Berl) 2012; 222: 633-43.

30 American Psychiatric Association. Diagnostic and Statistical Manual of Mental Disorders (4th edn) (DSM-IV). APA, 1994.

31 Hulka LM, Wagner M, Preller KH, Jenni D, Quednow BB. Blue-yellow colour vision impairment and cognitive deficits in occasional and dependent stimulant users. Int J Neuropsychopharmacol 2013; 16: 535-47.

32 Preller KH, Ingold N, Hulka LM, Vonmoos M, Jenni D, Baumgartner MR, et al. increased sensorimotor gating in recreational and dependent cocaine users is modulated by craving and attention-deficit/hyperactivity disorder symptoms. Biol Psychiatry 2013; 73: 225-34.

33 Perez de Los Cobos J, Sinol N, Puerta C, Cantillano V, Lopez Zurita C, Trujols J. Features and prevalence of patients with probable adult attention deficit hyperactivity disorder who request treatment for cocaine use disorders. Psychiatry Res 2011; 185: 205-10.

34 Swendsen JD, Merikangas KR. The comorbidity of depression and substance use disorders. Clin Psychol Rev 2000; 20: 173-89.

35 Wittchen $\mathrm{HU}$, Wunderlich U, Gruschwitz S, Zaudig M. SKID-I. Strukturiertes Klinisches Interview für DSM-IV Achse I: PSychische Störungen. [SCID-I. Structured Clinical Interview for DSM-IV Axis I Disorders]. Hogrefe, 1997.

36 Quednow BB, Kuhn KU, Hoenig K, Maier W, Wagner M. Prepulse inhibition and habituation of acoustic startle response in male MDMA ('ecstasy') users, cannabis users, and healthy controls. Neuropsychopharmacology 2004; 29: 982-90.

37 Lehrl S. Mehrfachwahl-Wortschatz-Intelligenztest (MWT-B) (4th edn). Hogrefe, 1999.

38 Sussner BD, Smelson DA, Rodrigues S, Kline A, Losonczy M, Ziedonis D. The validity and reliability of a brief measure of cocaine craving. Drug Alcohol Depend 2006; 83: 233-7.

39 Heatherton TF, Kozlowski LT, Frecker RC, Fagerstrom KO. The Fagerstrom Test for Nicotine Dependence: a revision of the Fagerstrom Tolerance Questionnaire. Br J Addict 1991; 86: 1119-27.

40 Beck AT, Ward $\mathrm{CH}$, Mendelson M, Mock J, Erbaugh J. An inventory for measuring depression. Arch Gen Psychiatry 1961; 4: 561-71.

41 Rosler $M$, Retz W, Retz-Junginger $P$, Thome J, Supprian $T$, Nissen $T$, et al. Tools for the diagnosis of attention-deficit/hyperactivity disorder in adults. Self-rating behaviour questionnaire and diagnostic checklist [In German]. Nervenarzt 2004; 75: 888-95.
42 Strauss E, Sherman EMS, Spreen O. A Compendium of Neuropsychological Tests: Administration, Norms, and Commentary. Third Edition. Oxford University Press, 2006.

43 Helmstaedter C, Lendt M, Lux S. Verbaler Lern- und Merkfähigkeitstest [Verbal Learning and Memory Test]. Beltz, 2001.

44 Wechsler DA. Wechsler Memory Scale (3rd edn) Manual. Psychological Corporation, 1997.

45 Kemps E, Tiggemann M. A Cognitive experimental approach to understanding and reducing food cravings. Curr Dir Psychol Sci 2010; 19: 86-90.

46 Sayette MA, Schooler JW, Reichle ED. Out for a smoke: the impact of cigarette craving on zoning out during reading. Psychol Sci 2010; 21: 26-30.

47 Cooper GA, Kronstrand R, Kintz P. Society of Hair Testing guidelines for drug testing in hair. Forensic SCi Int 2012; 218: 20-4.

48 Hoelzle C, Scheufler F, Uhl M, Sachs H, Thieme D. Application of discriminant analysis to differentiate between incorporation of cocaine and its congeners into hair and contamination. Forensic Sci Int 2008; 176: 13-8.

49 Substance Abuse and Mental Health Services Administration. Mandatory guidelines for federal workplace drug testing programs. Federal Register 2008; 73: 71858-907.

50 Hautzinger $\mathrm{M}$, Bailer $\mathrm{M}$, Worall $\mathrm{H}$, Keller F. Beck-Depressions-Inventar (BDI). Testhandbuch. Zweite, überarbeitete Auflage [Beck Depression Inventory: Test Manual. Second Edition]. Huber, 1994.

51 Yochim B, Baldo J, Nelson A, Delis DC. D-KEFS Trail Making Test performance in patients with lateral prefrontal cortex lesions. J Int Neuropsychol Soc 2007; 13: 704-9.

52 Manes F, Sahakian B, Clark L, Rogers R, Antoun N, Aitken M, et al. Decisionmaking processes following damage to the prefrontal cortex. Brain 2002; 125: 624-39.

53 Owen AM, Evans AC, Petrides M. Evidence for a two-stage model of spatial working memory processing within the lateral frontal cortex: a positron emission tomography study. Cereb Cortex 1996; 6: 31-8.

54 Owen AM, Sahakian BJ, Semple J, Polkey CE, Robbins TW. Visuo-spatial short-term recognition memory and learning after temporal lobe excisions, frontal lobe excisions or amygdalo-hippocampectomy in man. Neuropsychologia 1995; 33: 1-24.

55 Janowsky JS, Shimamura AP, Kritchevsky M, Squire LR. Cognitive impairment following frontal lobe damage and its relevance to human amnesia. Behav Neurosci 1989; 103: 548-60.

56 Alexander MP, Stuss DT, Fansabedian N. California Verbal Learning Test: performance by patients with focal frontal and non-frontal lesions. Brain 2003; 126: 1493-503.

57 Benedict RH, Zivadinov R, Carone DA, Weinstock-Guttman B, Gaines J, Maggiore $C$, et al. Regional lobar atrophy predicts memory impairment in multiple sclerosis. AJNR Am J Neuroradiol 2005; 26: 1824-31.

58 Ersche KD, Jones PS, Williams GB, Robbins TW, Bullmore ET. Cocaine dependence: a fast-track for brain ageing? Mol Psychiatry 2012: 18: 134-5.

59 Ersche KD, Jones PS, Williams GB, Turton AJ, Robbins TW, Bullmore ET. Abnormal brain structure implicated in stimulant drug addiction. Science 2012; 335: 601-4.

60 Volkow ND, Fowler JS, Wolf AP, Hitzemann R, Dewey S, Bendriem B, et al. Changes in brain glucose metabolism in cocaine dependence and withdrawal. Am J Psychiatry 1991; 148: 621-6.

61 Volkow ND, Hitzemann R, Wang GJ, Fowler JS, Wolf AP, Dewey SL, et al Long-term frontal brain metabolic changes in cocaine abusers. Synapse 1992; 11: 184-90.

62 Gotlib IH, Joormann J. Cognition and depression: current status and future directions. Annu Rev Clin Psychol 2010; 6: 285-312.

63 Valera EM, Brown A, Seidman LJ. Neuropsychology of ADHD and other disorders of childhood. In The Neuropsychology of Mental Illness (eds EM Valera, A Brown, ᄂ Seidman): 285-99. Cambridge University Press, 2010.

64 Shen $\mathrm{LH}$, Liao MH, Tseng YC. Recent advances in imaging of dopaminergic neurons for evaluation of neuropsychiatric disorders. J Biomed Biotechnol 2012; 2012: 1-14.

65 Liston C, Malter Cohen M, Teslovich T, Levenson D, Casey BJ. Atypical prefrontal connectivity in attention-deficit/hyperactivity disorder: pathway to disease or pathological end point? Biol Psychiatry 2011; 69: 1168-77.

66 Moeller KE, Lee KC, Kissack JC. Urine drug screening: practical guide for clinicians. Mayo Clin Proc 2008; 83: 66-76.

67 Curran HV. Is MDMA ('Ecstasy') neurotoxic in humans? An overview of evidence and of methodological problems in research. Neuropsychobiology 2000; 42: 34-41. 